\title{
Labially impacted maxillary canine - a case report
}

\author{
Canin maxilar inclus vestibular - prezentare de caz
}

\author{
Mioara V. Decusară ${ }^{1}$, Camelia A. Szuhanek², \\ Cristina Molnar Varlam ${ }^{3}$, Cerasella D. Șincar ${ }^{1}$ \\ ${ }^{1}$ Departamentul de Medicină Dentară, Facultatea de Medicină și Farmacie, \\ Universitatea "Dunărea de Jos", Galați, România \\ ${ }^{2}$ Catedra de Ortodonție, Facultatea de Medicină și Farmacie, \\ Universitatea "Victor Babeș", Timișoara, România \\ ${ }^{3}$ Facultatea de Medicină Dentară, Universitatea de Medicină, Farmacie, \\ Științe și Tehnologie „George Emil Palade“, Târgu Mureş, România
}

\begin{abstract}
Introduction. Dental impactation is a dental eruption abnormality in which the tooth cannot erupt due to the influence of loco-regional, general and genetic factors. Maxillary canines can often remain impacted and can cause migration or pathological root resorbtion of adjacent teeth, dentigerous cyst formation, shortening the length of the dental arch, which requires the intervention of surgical-orthodontic treatment.

Objective. In this paper we presented the orthodontic treatment performed for the correction of the eruption axis of an impacted maxillary canine, which has determined the malocclusion of the lateral incisor and the risk of its pathological root resorbtion.

Discussion. After 34 months of orthodontic treatment, the alignment of 23 and 22 was obtained, a relatively balanced occlusion (considering that the patient refused to apply the fixed orthodontic device to the mandibular arch), the orthodontic dental movement being evaluated by repeated radiological examinations at an interval of 10-12 months.
\end{abstract}

Keywords: labially impacted maxillary canine, orthodontic treatment

\section{REZUMAT}

Introducere. Incluzia dentară este o anomalie dentară de erupție în care dintele nu poate erupe din cauza influenței unor factori loco-regionali, generali și genetici. Caninii maxilari pot rămâne frecvent incluși intraosos și pot determina migrarea sau rizaliza dinților vecini, formarea de chisturi dentigere, scurtarea lungimii arcadei dentare, ceea ce impune interventia tratamentului chirurgical-ortodontic.

Obiective. În acest articol, este prezentat tratamentul ortodontic efectuat pentru corecția axului de erupție a unui canin maxilar inclus vestibular, care a determinat malocluzia incisivului lateral, cu riscul de rizaliză patologică a acestuia.

Discuții. După 34 luni de tratament ortodontic, s-a obținut alinierea lui 22 și 23 și ocluzie relative echilibrată (având în vedere că pacientul a refuzat aplicarea aparatului ortodontic fix la arcada dentară mandibulară), deplasările ortodontice fiind evaluate radiologic la intervale de 10-12 luni.

Cuvinte cheie: canin maxilar inclus vestibular, tratament ortodontic

\section{INTRODUCERE}

Incluzia dentară este o tulburare de erupție dentară ca urmare a acțiunii unor factori loco-regionali, generali și genetici. Cel mai frecvent afectați sunt caninii maxilari, care pot rămâne incluşi pentru o perioadă de timp după vârsta de erupție sau pot erupe ulterior ectopic (palatinal sau vestibular) $(1,2)$.

Dintre cauzele incluziei caninilor maxilar, se pot enumera $(3,4,5,6)$ :

- devierea de la calea de erupție determinată de existența unui obstacol (caninul de lapte, fără rizaliză fiziologică, formațiune chisti- 
că sau tumorală, dinte supranumerar, odontom, poziția anormală a mugurelui dentar, dilacerația radiculară)

- drumul lung de erupție, care începe aproape de podeaua orbitei, motiv pentru care sunt mari șanse ca uneori „să se abată de la cale“ sau ,să-și piardă drumul““

- înghesuirea dentară care afectează dentiţia mixtă timpurie: spațiu insuficient pentru ca incisivul lateral să migreze labial între rădăcina incisivului central şi caninii de lapte, astfel încât erupția va fi linguală față de dinții adiacenți. $O$ situație asemănătoare se creează atunci când molarul secund de lapte este extras precoce, primul molar permanent migrează mezial în spațiul disponibil, astfel încât al doilea premolar se palatinizează, putând modifica calea de erupție a caninului.

- un traumatism care a provocat mișcarea incisivului lateral sau mișcarea caninului neerupt

- absența congenitală a incisivilor laterali sau incisivi laterali nanici, în formă de con

- creștere excesivă la baza osului maxilar

- anchiloza dentară.

Pentru diagosticul incluziei caninilor maxilari, este importantă asocierea între examenul clinic (inspecție, palpare, relația cu dinții vecini), anam-
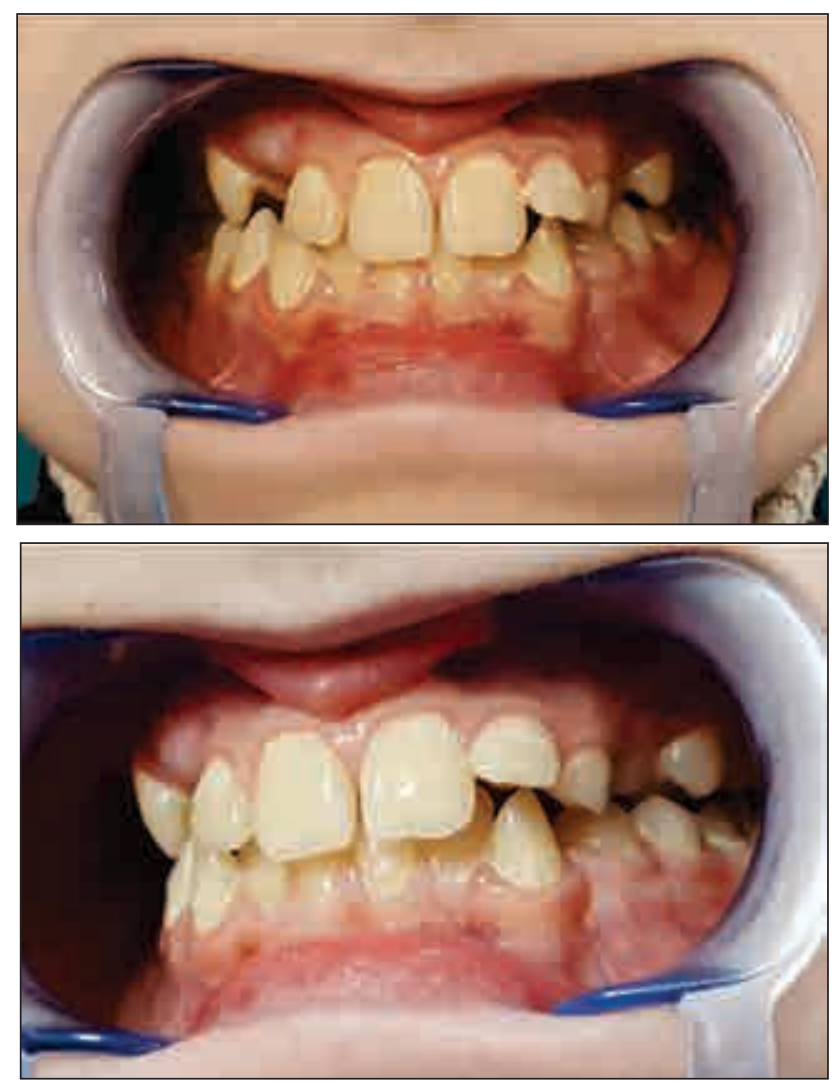

neza amănunțită și examenul radiografic (ortopantomograma sau CBCT). Diagnosticul precoce poate minimaliza o parte dintre problemele determinate de incluzia de canin, cum ar fi rizaliza patologică a incisivilor laterali, anchiloză, infecții, resorbția internă etc. $(4,7,10)$. Tratamentul chirurgical-ortodontic al caninilor incluși urmărește descoperirea chirurgicală a coroanei caninilor, aplicarea aparatelor fixe ortodontice și alinierea în poziția corectă, în funcție de poziţia intraosoasă și relația cu dinții vecini.

\section{PREZENTAREA CAZULUI}

În acest articol, este prezentat tratamentul ortodontic efectuat pentru corecția axului de erupție a unui canin maxilar inclus, care a determinat malocluzia incisivului lateral, cu riscul de rizaliză patologică a acestuia.

Este cazul unui adolescent de 14 ani, trimis de medicul stomatolog curant ca urmare a vestibuloînclinației lui 22, cu întârzierea erupției caninilor maxilari permanenți și persistența lui 63. La examenul clinic, s-au observat (fig. 1):

- dentiţie mixtă (fiind prezent 63, fără mobiltate fiziologică)
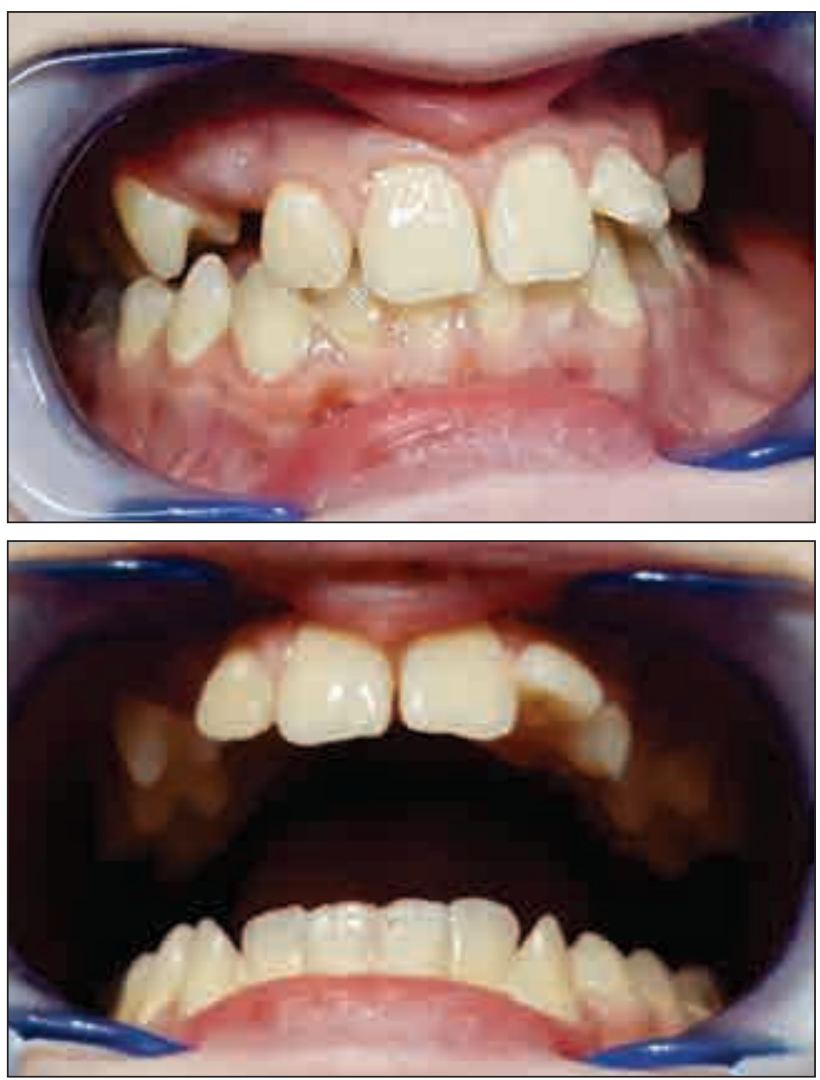

FIGURA 1. Aspectul arcadelor dentare din normă frontală şi laterală la începutul tratamentului ortodontic 
- pațiul redus pentru erupția lui 13, coroana fiind vizibilă și palpabilă vestibular

- vestibulo-înclinarea accentuată a lui 12 (în unghi de $45^{\circ}$ )

- relații neutrale în sens sagital

- angrenaje inverse între 15-45 şi 24-34 şi laterodeviația liniei interincisive maxilare de $2 \mathrm{~mm}$ față de cea mandibulară

- supraacoperire frontală de $1 / 2$.

Deoarece am presupus că înclinarea vestibulară a lui 22 este determinată de caninul maxilar inclus, a fost recomandată efectuarea unui examen de tip CBCT pentru arcada maxilară. Examenul tomografic a arătat devierea spre mezial a căii de erupție a lui 23 și poziția ectopică vestibulară a acestuia, coroana sa fiind deasupra rădăcinii 22 , fără a-i produce rizaliză patologică. Fenomenul a determinat rămânerea vestibulară intraosoasă a lui 23 , determinând presiune asupra rădăcinii lui 22 , ceea ce s-a materializat clinic cu vestibulo-înclinarea accentuată (aproximativ 45 de grade) a coroanei 22 (fig. 2).

Planul de tratament chirurgical ortodontic a fost:

- expunerea chirurgicală a coroanelor lui 13 și 23 și extracția lui 63

- aplicarea unui aparat ortodontic cu bracketuri SWT la arcada dentară maxilară, pentru alinierea dentară, realizarea spațiului pentru erupția caninilor permanenți, corectarea axului de erupție de 23 , prin mișcare ortodontică distală și vestibulară a lui
23, pentru protejarea rădăcinii și apexului lui 22 (fig. 3). Nu s-a aplicat de la începutul tratamentului bracketul pe 22, pentru a nu fi generate forțe ortodontice prin intermediul aparatului ortodontic, care să-i modifice axul coronoradicular (fig. 3).

Pe parcursul tratamentului, au fost efectuate radiografii periapicale pentru controlul deplasărilor ortodontice ale incisivului lateral și caninului maxilar de partea stângă (fig. 4).

La 28 luni de la începutul tratamentului ortodontic, a fost efectuată o ortopantomogramă de control, pentru evidențierea în ansamblu a statusului dento-parodontal (ce a impus modificarea poziției bracketului de pe 23, pentru aliniere, și corectarea axului coronoradicular a acestuia) (fig. 5).

După obținerea alinierii dentare maxilare și a relaţiilor ocluzale stabile în sens sagital, transversal și vertical, la 34 de luni de tratament ortodontic, a fost îndepărtat aparatul ortodontic (fig. 6).

\section{DISCUȚII}

Caninii maxilari erup între 11 şi 13 ani, au o traiectorie lungă și complexă de erupție (din porțiunea superioară a foselor canine), astfel încât influența unor factori generali sau loco-regionali poate determina incluzia acestora. Prognosticul caninilor incluși depinde de poziția acestora în raport cu dinții vecini și cu osul alveolar, trebuind luat în considerare și faptul că nu întotdeauna pot fi redresați ortodontic. Din acest motiv, tratamen-
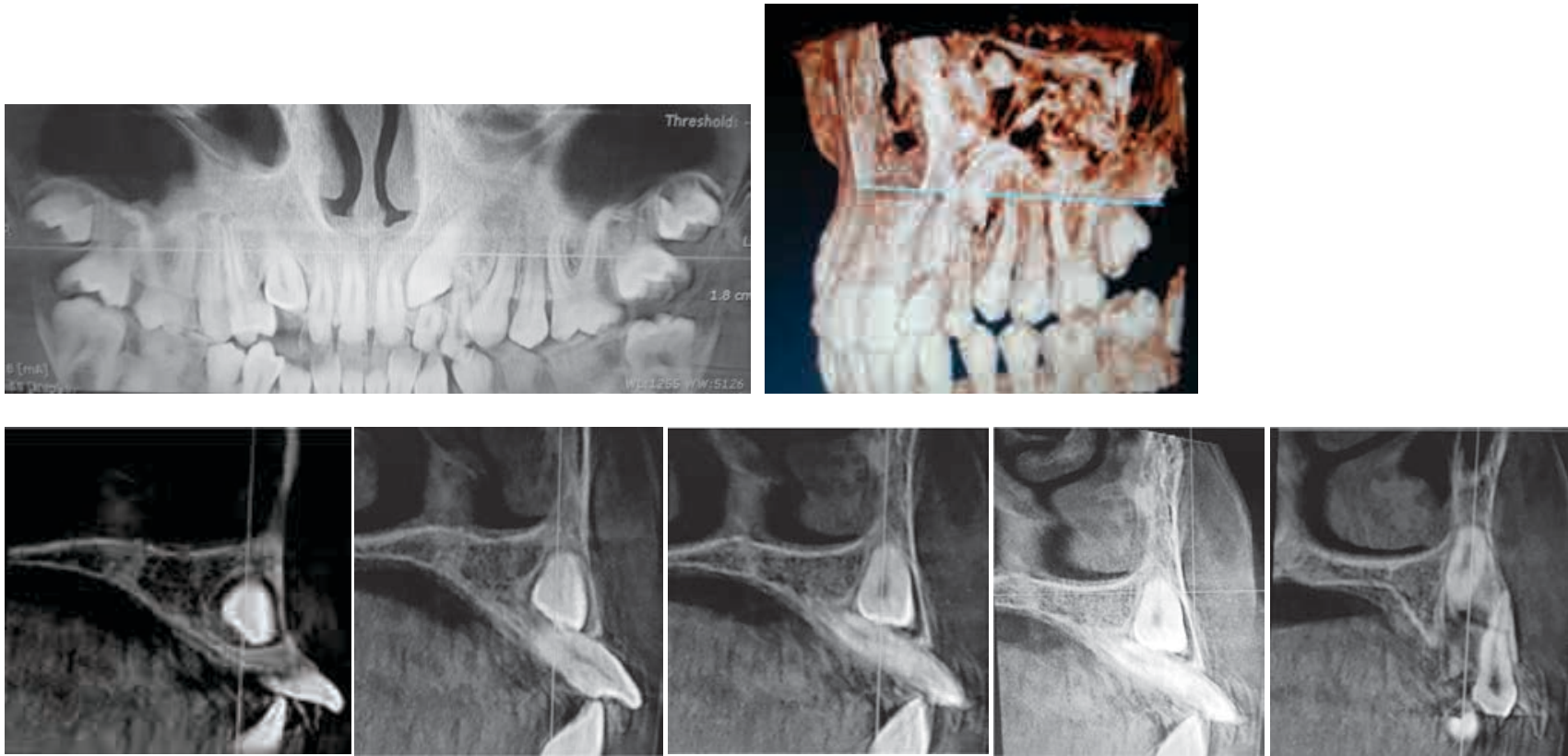

FIGURA 2. Imagini selectate din CBCT, care evidențiază poziția lui 23 inclus vestibular, deasupra rădăcinii lui 22, fără a-i produce resorbția radiculară patologică 

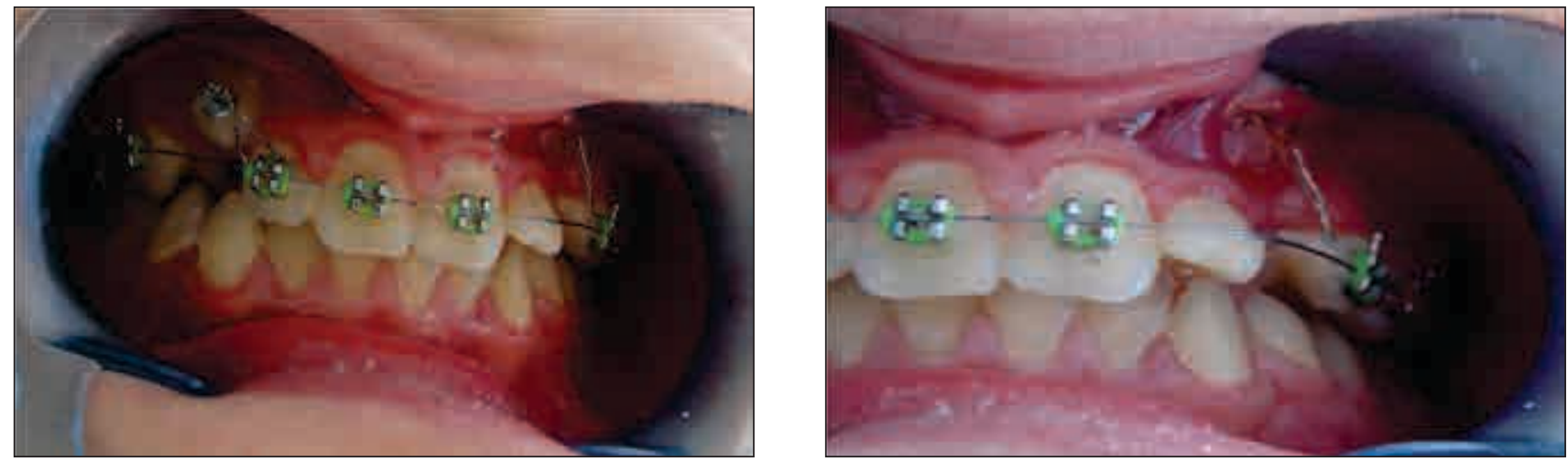

FIGURA 3. Aspectul arcadei dentare maxilare la începutul tratamentului ortodontic

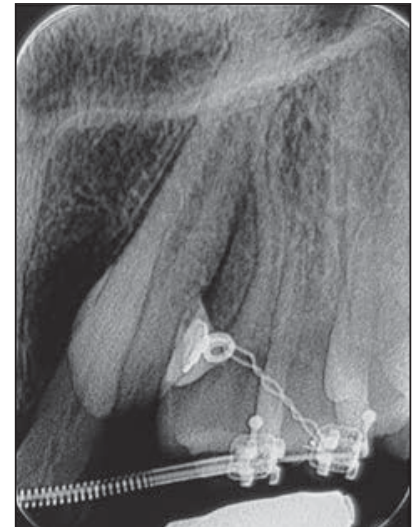

(a)

FIGURA 4. Radiografii periapicale de control la 10 luni (a) şi la 20 luni (b) de la începutul tratamentului ortodontic

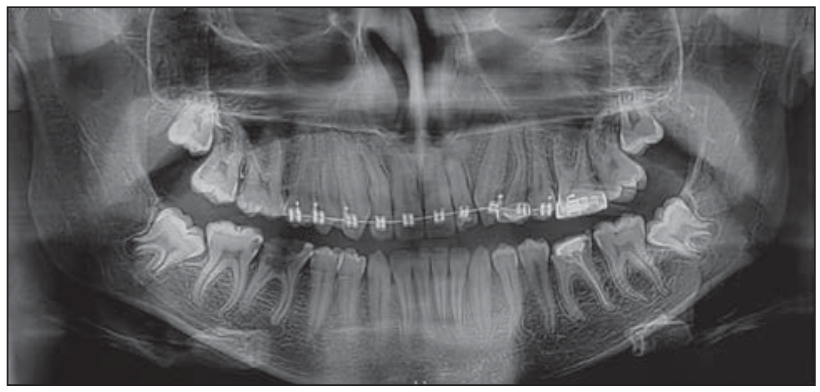

FIGURA 5. Ortopantomograma pacientului după 28 luni de la începutul tratamentului
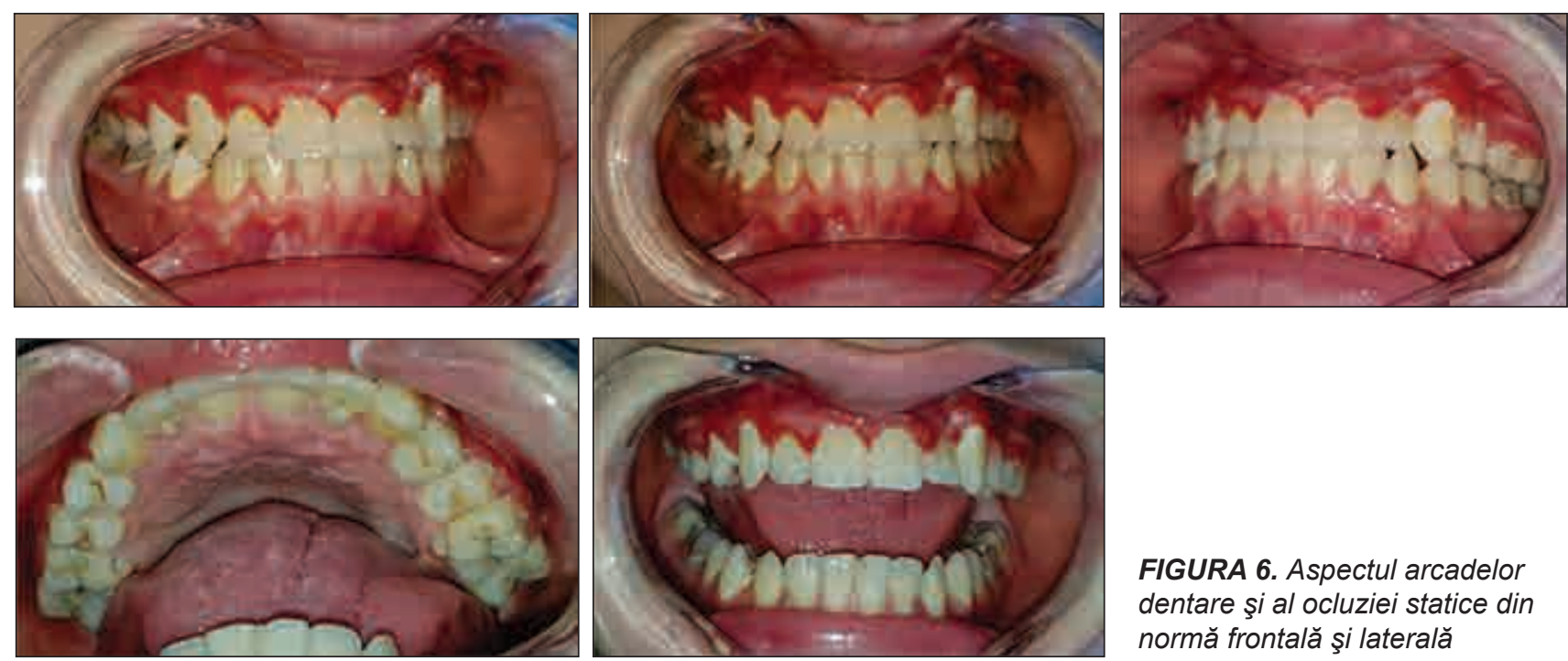

FIGURA 6. Aspectul arcadelor dentare şi al ocluziei statice din normă frontală şi laterală

tul incluziei dentare poate reprezenta o provocare pentru medicul ortodont, având în vedere complexitatea şi gravitatea cazurilor (mai ales cele generate de caninii maxilari), dar și o provocare pentru pacienți, dacă se ține cont de: durata tratamentului, investiţia financiară și, nu în ultimul rând, stresul terapeutic în sine $(4,7,8)$. Tehnica radiologică actuală (CBCT) ajută la evidențierea poziției dinților incluși și a relației cu țesuturile înconjurătoare, precum și la elaborarea planului de tratament chirurgical-ortodontic și stabilirea cât mai precisă a direcției forțelor care trebuie aplicate pentru redresarea caninilor incluși $(4,9,10)$.

\section{CONCLUZII}

Având în vedere incluzia vestibulară a lui 23, deasupra rădăcinii incisivului lateral, tratamentul 
chirurgical-ortodontic a urmărit deplasarea ortodontică spre vestibular și apoi spre distal a caninului și evitarea resorbției patologice a rădăcinii lui 22. După 34 de luni de tratament ortodontic, s-a obținut alinierea dinților malpoziționați și o oclu- zie relativ echilibrată (având în vedere că pacientul a refuzat aplicarea aparatului fix și la arcada mandibulară), mișcările ortodontice dentare fiind evaluate prin examinări radiologice repetate la intervale de 10-12 luni.

Conflict of interest: none declared Financial support: none declared

\section{BIBLIOGRAFIE}

1. Jacobs SG. Localization of the unerupted maxillary canine: how to and when to. Am J Orthod Dentofacial Orthop. 1999;115:314-22.

2. Decusară M, Grecu GP, Șincar DC. Aspects regarding the particularities of orthodontic treatment of ectopic maxillary canine teeth in the adult patient. Romanian Journal of Oral Rehabilitation 2020;12(3):41-47.

3. Becker A. The orthodontic treatment of impacted teeth. Martin Dunitz, 1998.

4. Vilarinho MA, de Lourdes Sá de Lira A. Palatally impacted canine: diagnosis and treatment options. Braz J Oral Sci. 2010;9(2):70-76.

5. Johnson D. Periodontic and orthodontic treatment in adults. Am J Orthod Dentofacial Orthop. 2003;123(2):13.

6. Brin I, Solomon Y, Zilberman Y. Trauma as a possible etiologic factor in maxillary canine impaction. Am J Orthod Dentofacial Orthop. 1993;104:132-7.
7. Cati G, Ghobadlu J, Nieri M, Clauser C. Factors associated with the duration of forced eruption of impacted maxillary canines: a retrospective study. Am J Orthod Dentofacial Orthop. 2006; 130:349-56.

8. Ngan P, Hornbrook R, Weaver B. Early timely management of ectopically erupting maxillary canines. Semin Orthod. 2005; 11:152-63.

9. Kokich VG. Surgical and orthodontic management of impacted maxillary canines. Am J Orthod Dentofacial Orthop. 2004; 126:278-83.

10. Decusară M, Șincar DC, Popa GV. Aspecte clinico-terapeutice în incluzia dentară. Revista Română de Stomatologie 2017; 63(3):124-128. 